\title{
The Methodology of Normative Policy Analysis
}

\section{Citation}

Robert, Christopher, and Richard Zeckhauser. 2011. The Methodology of Normative Policy Analysis. HKS Faculty Research Working Paper Series RWP11-004, John F. Kennedy School of Government, Harvard University

\section{Published Version}

http://web.hks.harvard.edu/publications/workingpapers/citation.aspx?Publd=7589

\section{Permanent link}

http://nrs.harvard.edu/urn-3:HUL.InstRepos:4669672

\section{Terms of Use}

This article was downloaded from Harvard University's DASH repository, and is made available under the terms and conditions applicable to Other Posted Material, as set forth at http:// nrs.harvard.edu/urn-3:HUL.InstRepos:dash.current.terms-of-use\#LAA

\section{Share Your Story}

The Harvard community has made this article openly available.

Please share how this access benefits you. Submit a story.

Accessibility 


\section{The Methodology of Normative Policy Analysis Faculty Research Working Paper Series}

\section{Christopher Robert}

Harvard Kennedy School

\section{Richard Zeckhauser}

Harvard Kennedy School

\section{January 2011 RWP11-004}

The views expressed in the HKS Faculty Research Working Paper Series are those of the author(s) and do not necessarily reflect those of the John F. Kennedy School of Government or of Harvard University. Faculty Research Working Papers have not undergone formal review and approval. Such papers are included in this series to elicit feedback and to encourage debate on important public policy challenges. Copyright belongs to the author(s). Papers may be downloaded for personal use only. 


\title{
The Methodology of Normative Policy Analysis*
}

\author{
Christopher Robert and Richard Zeckhauser \\ John F. Kennedy School of Government, Harvard University
}

December 31, 2010

This is a preprint of an article accepted for publication in Journal of Policy Analysis and Management (C) 2010 by the Association for Public Policy Analysis and Management

\begin{abstract}
$\underline{\text { Abstract }}$
Policy analyses frequently clash. Their disagreements stem from many sources, including models, empirical estimates, and values such as who should have standing and how different criteria should be weighted. We provide a simple taxonomy of disagreement, identifying distinct categories within both the positive and values domains of normative policy analysis. Using disagreements in climate policy to illustrate, we demonstrate how illuminating the structure of disagreement helps to clarify the way forward. We conclude by suggesting a structure for policy analysis that can facilitate assessment, comparison, and debate by laying bare the most likely sources of disagreement.
\end{abstract}

\section{INTRODUCTION}

Policy disagreements are often multi-faceted and seemingly intractable. There are many different ways to disagree and many dimensions along which to do so. The underlying sources of disagreement easily become tangled and confused, making it difficult to identify the potential points of actual agreement or to conduct the give-and-take of compromise. Making matters worse, advocates of contested policies may strategically misrepresent their preferences or beliefs if they think that, in the ultimate tug and haul of policy debate, such dissembling will lead to an outcome they prefer. While no magic wand can simplify the complex or prevent strategic argument, this essay seeks to illuminate the underlying structure of policy disagreement with the expectation that such understanding can help lead to generally better policies.

The health insurance reform debate of 2009-10, which was centered in the U.S. Congress but engaged many players from the broader society, is a poster child for the types of complex, unresolved,

\footnotetext{
* The authors would like to thank Doug Besharov, Michael Blomfield, David Ellwood, Lant Pritchett, Blaine Saito, Tom Schelling, Jane Silfen, Rob Stavins, Gernot Wagner, David Weimer, and five anonymous reviewers for extensive and helpful comments and conversations.
} 
and confounding policy disagreements we have in mind. As is common with such disagreements, the outcome, which satisfied no one, fell far short of its potential.

Milton Friedman's classic essay, The Methodology of Positive Economics (1953), provides some helpful insight. Friedman followed John Neville Keynes (1904) (the father of Friedman's predecessor and nemesis John Maynard Keynes) in stressing the importance of distinguishing positive from normative sources of disagreement. "The confusion Keynes laments is still so rife and so much of a hindrance," Friedman observes, that he must begin his own methodological essay with the distinction between positive and normative analysis, between analysis that seeks to clarify what is and analysis that seeks to identify what action should be taken.

We wish to extend this distinction beyond the field of economics to the general realm of policy. Therefore, taking Friedman's well-known essay as a departure point, we examine "The Methodology of Normative Policy Analysis." We believe that parsing the positive and normative sources of disagreement can lead to progress. Thus, we seek a rational discourse on policy. ${ }^{1}$ We build on the basic insights of Friedman and Keynes to create a more complete taxonomy of disagreement, particularly as it arises in the broader policy domain. In this respect, we follow less the tradition of Friedman and more the tradition of Keynes, for we cannot cast aside questions of values to focus exclusively on the positive science as Friedman did. As all policy prescriptions must consider values, so too must we.

Our taxonomy can be used to identify various viewpoints and organize policy discourse. We illustrate with examples drawn from several policy areas, drawing most heavily from climate policy. We select this area because it has three critical qualities: 1 . It is of great policy import. ${ }^{2} 2$. It is rife with disagreement. And 3. Clarity on its sources of disagreement has the potential to yield significant returns. We conclude by suggesting a structure for policy analysis that can facilitate assessment, comparison, and debate by making clear the likely sources of disagreement. The basic idea is simple: to lay bare the positive and values choices underlying one's analysis.

We believe that better understanding of the true and potential sources of disagreement can lead to better policy in several ways. When disagreements can be clearly identified within the positive domain, we might agree on further investigation in order to move toward resolution. When disagreements lie within the values domain, we can seek mutually-beneficial compromise even when we cannot reach agreement. When instead there is a lack of clarity over the sources of disagreement, we might share information less readily, particularly if we fear underlying values differences. This can cause disagreements to persist even in cases where, if we all shared information without strategic selectivity, we would actually come to agree. This might happen, for instance, if we were actually in agreement on values but did not know that, and differing information led us to differing policy conclusions. Throughout this paper, we will elaborate on these and other potential advantages to clarity.

\footnotetext{
${ }^{1}$ We believe that neither Friedman nor either Keynes would regard this concept as an oxymoron.

${ }^{2}$ Climate skeptics would agree on its import because nations are likely to devote significant resources to avoiding what they regard to be a nonproblem, or a likely nonproblem.
} 
The remainder of this paper is organized as follows. The next section more fully discusses the setting in which disagreement arises, preparing the stage for our proposed framework. The following section introduces the basic framework, then elaborates each type of disagreement in turn. Alternating sub-sections present examples from climate policy. The final section concludes with a proposed structure for normative policy analysis.

\section{Analysts and Analysis}

The sensitive reader will already have inferred much about our views on the nature of policy analysis and on the orientation of policy analysts. Still, we wish to be explicit. There is an interplay between analyst and analysis, and our understanding regarding the nature of both serves as the foundation for the arguments we make throughout this paper.

To start, we admit to having both academic and idealistic leanings, but stopping far short of being Pollyannas. We recognize that there are strong political and strategic dimensions to disagreement in the policy sphere. These are reflected in the differing orientations of the analysts themselves, which we imagine arrayed along a hypothetical continuum anchored by archetypes at either extreme. What distinguishes an analyst's position along this continuum is his or her relative commitment to facts or models - the less inherently subjective science of the matter - versus values.

The dispassionate analyst, the archetype on one end of the continuum, is driven by facts and models. The advocate-analyst, on the other end, is predominantly driven by values. (For mnemonic purposes and expository ease, we will speak of the dispassionate analyst as female and of the advocateanalyst as male.) This is not to say, of course, that the dispassionate analyst is totally insensitive to values, for no analysis can proceed from the descriptive to the prescriptive without a values underpinning. Nor is it to say that the advocate-analyst is insensitive to the facts of the matter. Even the most passionate believer in a policy could be dissuaded if its unintended consequences pushed hard against his intended results. For example, supporters of more aggressive military action in Afghanistan might change their preference if they learned that such action would inflame the Muslim world and lead to more terrorist losses at home. Nevertheless, the advocate-analyst will promote a favored policy, applying more emphasis to values and less to predicted outcomes than the dispassionate analyst.

The advocate-analyst's values might spring from a variety of sources, both personal and professional. His upbringing, social position, moral code, or personal self-interest may drive his policy position. Alternatively, he may perceive a moral or fiduciary responsibility to a client or constituency, as will the lobbyist, business owner, politician, or member of an organization that has well-defined values or interests. Thus, the values of the advocate-analyst may be parochial or societal, self- or otherinterested. He could hold them for reasons as base as mercenary interest or as noble as moral obligation.

While the dispassionate analyst will be less wed to particular values, she might favor certain models and methodologies. She might also be anchored by hysteresis. Thus, having provided analysis on a particular subject in the past, she might feel the need to periodically defend her former model or 
position, if only for consistency or personal pride. If such path dependence is strong, the disagreements that emerge will tend to persist.

This notion of an analyst continuum has echoes throughout the policy literature. For example, Jenkins-Smith (1982) discusses the need for analysts to choose a role, with the "objective technician" role contrasted with client and issue advocacy roles. Likewise, when it comes to the closely related role of the scientist in the policy process, Pielke (2007) distinguishes between "the pure scientist," "the science arbiter," "the issue advocate," and "the honest broker of policy alternatives." Our continuum is intended to capture these kinds of typologies.

Some frameworks for understanding the policy process, such as the Advocacy Coalition Framework (ACF, Sabatier \& Weible, 2007), stress advocacy and the disagreements between advocates. Still, even the ACF admits to a role for research to occasionally stimulate "policy learning" and therefore policy change. It is this research within the ACF that we find most characteristic of policy analysis in general.

This brings us to what is meant by "policy analysis." As in Vining and Weimer (2005), the standard textbook treatment devotes an entire chapter or at least a section to the definition. Weimer (2002) describes the essence of policy analysis as "the systematic comparison of alternative policies in terms of social values," and Kraft and Furlong (2004) similarly describe policy analysis in terms of systematic and rational consideration of alternatives. Stokey and Zeckhauser (1978) talk more generally of a "rational decision maker who lays out goals and uses logical processes to explore the best way to reach those goals." These authors are all firmly in the dispassionate-analyst camp. They espouse the broad sense of what we consider to be policy analysis here, though we make a special effort to separate the values or goals from the positive analysis, and then to recognize further distinctions within those categories. ${ }^{3}$

This is a normative notion of policy analysis. Certainly other forms of analysis exist in the world, and other positive and normative views exist in the literature. Fischer and Forester (1993), for example, consider policy analysis to be fundamentally about argumentation. In their view, values permeate everything from the analyst's selection of data to his choice of language. We agree that no policy analysis can be values-free, and even that much analysis may be as Fischer and Forester describe. However, we argue that policy analysis should be values-agnostic in the sense that it is transparent about trade-offs between values. We believe this to be consistent with what Weimer (2005) calls "neutral competence" in policy analysis, and with what MacRae (1993) calls "reasoned proposal selection." And while MacRae limits reasoned selection to the case where disagreement arises only regarding means, not ends, we believe that rational analysis can proceed even in the presence of disagreement over goals. Moreover, we believe rational discourse to add even more value when disagreements span both the positive and values domains.

\footnotetext{
${ }^{3}$ Much of what is discussed here can be applied to program evaluation more generally. Certainly, much policy analysis amounts to program evaluation (as outlined, e.g., in Lipsey, Freeman, \& Rossi, 2004), and much program evaluation could benefit from the recommendations made here.
} 
Weimer and Vining (2005) and Jenkins-Smith (1982), among others, stress the importance of the client in policy analysis. We are more agnostic as to the client's role (if any). In our view, it does not matter from where values choices originate - whether a client, a constituency, or elsewhere. Regardless, there will be values and our claim is that it is best to be transparent about them. For want of a strong client orientation, however, what we call "policy analysis" might alternatively be called "policy research" (as in, e.g., Vining \& Weimer, 2005).

The contribution of analysis to the overall policy process may be modest. We admit that politics frequently plays the leading role in forging the major policies of the day, with analysis seeming to play only a bit part. We believe, however, that there is always a deep interaction between politics and analysis. Each facilitates the other, with politics helping to supply the values underpinning for analysis, and analysis helping to supply the information and clarity necessary to a well-functioning political process. While the link between policy analysis and actual policy is rarely direct, often policy evolves over time as analysis seeps into political argument and policy ideas. Analysis is rarely absent when policy is ultimately formed.

Political outcomes usually benefit when analysis is transparent, but transparency is by no means the rule. Our exemplar of a dispassionate analyst prefers transparency in both analysis and disagreement, and to base her recommendations on explicit values. When asked, she makes contingent recommendations, readily explains her model and reasoning, and shares her data. The advocate-analyst confronts a more challenging situation. Opacity may serve him better than clarity. Since it is hard to persuade people to change their values, he will often frame values differences as deriving from differences in models or data. He will employ transparency selectively, showing his hand only when it serves his preferred policies. He may even find disagreement useful as a means to mobilize supporters, boost their contributions, and renew their commitment to core values. Witness the contemporary American political arena.

The game escalates. The dispassionate analyst must protect her position. Recognizing the presence of advocate-analysts who are tilting their presentations, she must respond by presenting her assessments and values in the manner that will lead to the best objective policy. Even if she is completely values-neutral and objective, transparency is rarely her optimal strategy in response to others who are acting strategically. She must defend against their distortions. That is why, we believe, individuals who consider themselves to be dispassionate analysts often behave as contrarians, pushing back against whatever policy preference is being espoused.

Even if most players in the policy arena are predominantly dispassionate analysts at heart, the presence of some advocate-analysts - or even the expectation of such - may lead large numbers to tilt their analyses in the direction of advocacy, thereby clouding transparency in their underlying values and beliefs. In other words, strategic behavior is likely to be contagious. We believe this to be the situation that prevails in most policy areas, with the result being a persistent tangle of disagreement. Our expectation is that, if the elements in this tangle are identified and better understood, some of the knots can be untangled; smoother junctures can result. 


\section{A TAXONOMY OF DISAGREEMENT}

Policy analysis seeks to answer questions. On the most salient policy issues of the day, disagreement on answers is almost inevitable. As Friedman and Keynes point out, it is useful to distinguish between disagreement in the positive domain and disagreement in the values domain. ${ }^{4}$ Disagreements in these two domains are qualitatively different; different means are required to resolve them. Robert Levine (1963) makes a similar point, that we want to compare "values with values, and analyses with analyses." We concur, and go further. We identify several additional distinctions of importance within each of the positive and values domains. We believe that significant benefit will be reaped if the parties in a debate merely recognize and attend to these distinctions.

The positive domain concerns how the world is understood to work. We propose thinking in three categories. Positive analysis includes what portion of the world one is trying to understand (scope), what mechanisms explain the behavior of the world (model), and what estimates of model parameters are thought to obtain in particular contexts (estimate). Take, for example, a common policy debate among economists, namely of the virtues and vices of the minimum wage. Different analysts agree on some of these areas (such as scope and microeconomic model), but not on others (for instance, estimates for the elasticity of labor supply) (e.g., Card \& Krueger, 1994, 1997, 2000; Neumark \& Wascher, 2000).

Even when there is initial agreement within a category, just identifying that category can foster useful thinking. For instance, in the minimum wage context, we usually focus on the present outcomes for individuals subject to that wage today. But surely our scope could be larger. We might think forward to such issues as how the minimum wage will affect those individuals' incentives and prospects for advancement, or how it will affect the incentives for younger individuals whose future entry into the labor market might be at or near the minimum wage. Or we might think vertically, such as about how the minimum wage will affect the more skilled and better paid workers who complement or compete with those at the bottom of the wage scale.

Most policy debates, however, revolve around a strong element of differences in values. This could be seen clearly in the aforementioned debate over the appropriate structure of U.S. health insurance reform. Even allowing for strong elements of strategic posturing and political loyalty, it was remarkable that in the end, Republicans and Democrats in the Senate separated fully on legislation. Such separation could only occur if differences were significantly driven by ideology and values complemented by party loyalty, as opposed to estimates of elasticities or predictions about the effectiveness of competition. For example, the desirability of the so-called "public option" for individual health coverage appeared to depend much more on each legislator's sympathies for the public sector than on their understanding of the underlying models or estimates.

\footnotetext{
${ }^{4}$ The values domain concerns the bases for judging the outcomes of policy choices. Any normative or prescriptive analysis necessarily includes positive analysis, plus values. This includes what Keynes described as "art," or the application of positive and normative analysis in the world.
} 
The values domain leaves substantial room for disagreement over the worth of various outcomes. Once again, a three-category distinction seems helpful. The values domain includes decisions about who counts (standing), about what counts (criteria), and about how much the individuals and criteria count (weights). In the U.S. health insurance debate, disagreements arose in all three areas. On standing, a critical question was whether illegal aliens should be covered, in effect whether outcomes for them counted. A key disagreement on criteria arose over whether the size and role of the public sector should count in the analysis. And on weights a critical question was the balance between higher premiums for the young and healthy versus more coverage for the uninsured. These were all debates over how to value outcomes, but they can be parceled into different categories. (For a discussion of value issues in the health care debate, see Baicker \& Chandra, 2009; Editor, 2009; Pear \& Herszenhorn, 2009.)

Table 1. A taxonomy of disagreement

Positive disagreements can be over questions of:

Scope: what elements of the world one is trying to understand

Model: what mechanisms explain the behavior of the world

Estimate: what estimates of the model's parameters are thought to obtain in particular contexts

Values disagreements can be over questions of:

Standing: who counts

Criteria: what counts

Weights: how much different individuals and criteria count

Any positive analysis will tend to include elements of scope, model, and estimation, though often these elements intertwine; they frequently feature in an implicit or undifferentiated manner. Likewise, normative analysis will also include elements of standing, criteria, and weights, whether or not these distinctions are recognized. Separating these elements can be useful. To do so helps us to clarify our areas of disagreement, a first step on the way to the horse-trading of mutually-beneficial compromise. We will later discuss how new analysis can be designed in a way that enhances clarity and transparency from the outset.

The move from economic analysis to normative policy analysis, from Friedman and Keynes to the present effort, requires attention to issues that are distinctly important within the general policy arena. It may well be that economists, for example, frequently understand the bases of their disagreements. However, we believe that such recognition is much less likely when economists, lawyers, political advocates, and other types of analysts meet in the policy arena. With the mix of disciplines and perspectives, disagreements can become particularly opaque.

Sometimes the lack of clarity is intentional, as when the analyst's values are secreted into a purportedly positive analysis. Pielke (2007) calls this "stealth issue advocacy" in the context of scientific analysis, suggesting that it undermines scientific credibility. We agree, and believe that it threatens the credibility of policy analysis more generally. 
The situation is aggravated by the frequent tendency of analysts to invoke historical analogies in their arguments (capitalizing on the powerful availability heuristic, ${ }^{5}$ either consciously or unconsciously). The two (or multiple) sides will employ quite different historical examples, often extrapolating across situations that differ dramatically on many dimensions. Thus, most contemporary military undertakings by the United States get support by identifying similarities to World War II, and get attacked by showing relationships to the Vietnam War. Underlying any such analogy is an entire bundle of claims regarding the applicability of the prior case and its potential to lend predictive insight into the present one. Disentangling and critically examining these various claims can be a slow and difficult task, particularly in contrast to the speed and rhetorical power of the analogies themselves. While it may seem like the argument is won or lost in the mean time, we think it worth the time and trouble to parse such analogies into their constituent claims so that both disagreements and their potential resolutions gain clarity.

There are several important aspects of policy disagreement that we must, regrettably, leave aside. The first has to do with the process by which disagreement becomes entrenched, as individuals who start out with moderately divergent views gravitate to much more extreme and opposing positions. Within economics and political science, there is a literature that seeks to identify the reasons why rational (Bayesian) agents who start with common values might come to hold very different beliefs (Aumann, 1976; Dixit \& Weibull, 2007; Morris, 1995; Sunstein, 2009). These models either rely on differences in prior beliefs or on differences in information. Importantly, the two types of differences interact; no matter the original source of a difference in beliefs, people naturally seek out individuals and sources of information that further reinforce those beliefs. ${ }^{6}$ This may take the form of ensconcing oneself amid like-minded friends, colleagues, and news sources, all of which tend to reduce the unpleasant challenge and cognitive dissonance that comes with confronting opposing viewpoints. Combining these differences in information with the differences in personal interests that also tend to cluster by organization or group yields the well-known outcome that "where you stand depends on where you sit" (Miles, 1978). In our view, this tendency enhances the importance of the disciplined inquiry into the true sources of disagreement.

Another important aspect of policy disagreement that we must leave aside has to do with strategic disagreement on the policies that are preferred or supported. In the political maelstrom, individuals may choose to disagree even when they are in actual agreement on both facts and values. This is a different class of disagreement altogether, quite unlike positive or values disagreement. The severe separation of Democratic and Republican votes on various measures surrounding the 2010 U.S. financial regulation bill - on most votes Republicans were united in opposition, and an overwhelming majority of Democrats were in favor - reveals such strategic behavior. Party loyalty, and its potential

\footnotetext{
${ }^{5}$ Decision-makers are most influenced by facts or arguments that spring easily to mind (Tversky \& Kahneman, 1974). Historical analogies tend to be powerful in this regard.

${ }^{6}$ This is an explicit feature of the Advocacy Coalition Framework, where participants in the policy process seek to ally themselves with others who share the same "policy core beliefs" (Sabatier \& Weible, 2007).
} 
strategic payoffs, no doubt trumped the way many legislators would have voted if left to their own or their constituents' preferences and beliefs. Strategic policy disagreements of this nature, however important in the real world, are a phenomenon beyond the scope of this essay. Our focus is on situations where actual differences in values and beliefs drive differences in policy preferences.

However, we believe that the approach we advocate here - careful inquiry into the sources of disagreement - is useful even in cases where individuals misrepresent or selectively reveal their own values and beliefs. After all, misrepresentation and selective revelation are more easily sustained when disagreement remains murky and ill-defined. By shining a light on the true sources of disagreement, individual positions are naturally laid bare. This may make such less-than-forthcoming actors uncomfortable, and even render some strategic positions untenable (as when a politician is forced to rest his case on a particular fact that is subsequently demonstrated to be incorrect).

The following sections, then, discuss each type of positive and values disagreement in turn. For each, our strategy is to begin in general terms and end with a series of concrete examples from climate policy. Before beginning with the subject of positive disagreements, we briefly introduce the topic of climate policy.

\section{Examples from Climate Policy: An Introduction}

Few policy areas are more vexing than climate change. Policymakers must grapple with tremendous complexities in the underlying physical science on the one hand, and with the potentially massive and poorly understood human and economic implications of action or inaction on the other. Even the very presence or absence of scientific agreement stirs a debate that inflames passions among experts, and that stokes confusion among the voting public.

The review of "expert credibility" presented by Anderegg et al. (2010) exemplifies the problem. This analysis attempts to quantify the oft-made claim that those who deny or minimize anthropogenic climate change (we call them "skeptics") are few in number and, on the whole, less expert than the vast majority of scientists who affirm the basic scientific reality of climate change. The quantitative evidence presented is more limited, however. Skeptics are shown to be less published and less cited, but this could itself be the result of the anti-skeptic publication bias often claimed by skeptics. As discussed in Boykoff and Boykoff (2004) and Pooley (2010, pp. 33-51), however, it is surely the case that the skeptics' prominence in popular discourse vastly exceeds their prominence in scientific discourse; skeptics themselves readily admit that theirs is a distinctly minority view. While quantifying the precise level of scientific agreement remains a contentious issue, the extent of scientific consensus on the basic facts is striking to many scientists (as in, e.g., Oreskes, 2004a).

Thus, the most important disagreements do not lie between skeptics and believers. They arise among the many scientists, economists, and others who accept an extremely high likelihood that human activities are affecting the climate, but take different views as they grapple with the specifics. They debate the questions of what exactly is happening, how fast it is happening, and what the impacts will be; who should act, when, and how. The underlying debate is rich and textured. The examples we present offer only an overview of the key disagreements as we see them. 
Most climate-change issues tend to be rooted in the physical sciences, and yet all require a policy debate that involves economic, political, legal, and ethical dimensions. There is a clear need for policy analysis that somehow accounts for all of these dimensions; and economists, legal scholars, and others have charged into the breach. As the debate has matured and new disciplinary perspectives have been brought to bear, there has been increasing recognition that the positive and values domains must be distinguished (as in, e.g., Dasgupta, 2007). We contribute to this effort by organizing the key sources of disagreement according to our taxonomy. Table 2 summarizes these sources, and the following sections discuss each in more detail. ${ }^{7}$

\footnotetext{
${ }^{7}$ Hulme (2009) offers a lengthier and more nuanced discussion of the deeper sources of climate policy disagreement. He presents thoughtful discussions of epistemology, value, and risk, as well as of the degree to which disagreements have roots in religious and historical ideas of climate, nature, and man's place in the world. While there is clear overlap between his approach and ours (e.g., we both point to differences in underlying valuation frameworks as one key source of policy disagreement, and we both view disagreement as potentially constructive and worthy of greater understanding), his emphasis tends toward deeper explanations specific to climate policy. Our emphasis is on more proximate sources of disagreement, an approach with greater potential for generality.
} 
Table 2. Climate policy: sources of disagreement

Positive disagreement: scope

Unit of analysis: global, regional, or national?

Actors: which persons, institutions, polities?

Costs and benefits: at what level of disaggregation?

Consider: which policy interventions? ...political feasibility? ...non-market or relative-price effects? ...strategic and behavioral responses to policy?

Positive disagreement: model

The physical science.

Quantifying and valuing economic impacts.

Projecting interventions' economic costs and benefits.

Accounting for uncertainty.

Positive disagreement: estimate

Physical science parameters.

Quantification and valuation parameters.

Intervention projection parameters.

Uncertainty parameters, including the pace of learning.

Values disagreement: standing

National vs. international analysis.

Generational time horizon.

Values disagreement: criteria

Market impacts.

Non-market or relative price impacts.

Fairness and justice.

Political feasibility.

Respect for nature.

Values disagreement: weights

Interpersonal: poor vs. rich, in terms of both countries and individuals.

Intertemporal: present vs. future generations; time preference or discount rate.

Uncertain or irreversible outcomes.

Errors of commission vs. errors of omission. 


\section{Positive disagreements}

\section{Disagreements over scope}

No analysis can include everything. Triage decisions must be made regarding what is essential and what is not. In this spirit, Stokey and Zeckhauser $(1978$, p. 18) identify appropriate simplification as key to "the art of model building." But the question of what is appropriate in any context can give rise to substantial disagreement.

Part of what drives the scope of analysis is the determination of what should be included. Values decisions regarding standing and criteria will underlie this determination, matters discussed in a later section. Pragmatic considerations also play a major role. What can be included? An analysis may be influenced by the analyst's set of skills, her access to data, or her time for research. But if the potentially omitted consideration is critical and the problem is important, analytic capability can be added, new data secured, and deadlines extended. Policy analysis always encounters tradeoffs among various goals, and one such tradeoff is between the intensity of the analysis and its reliability.

In the case of scope disagreements, it can be particularly difficult to separate the purely positive disagreements over the descriptive analysis on the one hand from the values disagreements over standing or criteria on the other. This distinction can be viewed as being between the ideal and the pragmatic approximation of that ideal. It is helpful to understand where we agree on what should be included from a values perspective (the ideal), even if we disagree vigorously on the practical tactics of analysis (the approximation).

When considering the effects of nearly any policy, scope can include effects that are short- or long-run, partial- or general-equilibrium, direct or strategic. While long-run, general-equilibrium, strategic analysis may be extremely sophisticated, we should not neglect more direct or short-run effects. As John Maynard Keynes (1923) indicated in his famous remark "in the long run we are all dead," long-run analysis may be a poor guide to short-run policy. Though neglecting the long-run is perhaps the more obvious danger, neglecting the short-run can be equally mistaken. Individual policies the U.S. financial system bail-out and health insurance reform packages come to mind - may favor one over the other, and the participants on opposite sides of the debate may well favor different time scales. However, good analysis will consider both short- and long-run effects when both are consequential.

While a problem's scope may include myriad dimensions of effect, the quest for appropriate simplification must always be kept in mind. With too much information, the model becomes intractable. With too little, it misses vital considerations and thus relevance. Direct effects are usually easily incorporated, but interactive effects - where the choices of other players are influenced - are often equally important. Being harder to predict and defend, such interactive effects are more likely to be omitted, even when significant.

Kousky and Zeckhauser (2009) identify the U.S. "Cash for Clunkers" program as a case where excessive simplification led to misguided policy. Because the program, or at least most analyses of it, failed to consider the negative environmental impact of producing new cars and decommissioning old 
ones, these analyses suffered from what the authors termed "scope neglect." Given the initial policy goals, subsequent policy assessments of even the environmental impact might well have reached the wrong conclusions because of the overly narrow scope.

Unfortunately, scope disagreements often become a pitched battle, with each side maneuvering to elevate the ground most favorable to their cause. This is particularly the case among advocateanalysts, who sometimes obfuscate by mixing what is technical or pragmatic with what is based on values. However, a hard-nosed dedication to disentangling the disagreement can help to illuminate the true sources of discord and suggest a way forward.

Once disagreement over scope in the positive domain has been clearly addressed, questions of empirics and reason take over. That is the realm to which Friedman and J.N. Keynes were themselves most dedicated. Before turning to disagreements in that area, we illustrate scope disagreements with several examples from climate policy.

Examples from climate policy: disagreements over scope

Climate policy presents an exceptionally wide range of challenging scope issues. Perhaps most fundamentally, there is the question of whether analysis should be conducted at the global, regional, national, or even sub-national level. Compelling forces pull in opposing directions. On the one hand, climate change is a fundamentally global challenge. All nations share a common atmosphere - a sort of global commons - and so actions within any nation have global consequences. As with any commons problem, coordination may be necessary to avoid the free-rider problems associated with divergence between individual and collective incentives (as argued, e.g., in Stern, 2007).

On the other hand, the potential actors clearly operate at the national or sub-national level, and there is no clear mechanism for global coordination. As Schelling (2006a) discusses, present-day and historical examples of large-scale international coordination - e.g., the World Trade Organization (WTO), European Union (EU), Organization of Petroleum Exporting Countries (OPEC), or North Atlantic Treaty Organization (NATO) - are not encouraging. Successful enforcement of multilateral agreements has not been a hallmark.

In the case of climate policy, the pessimism derived from historical examples is strongly reinforced because the nations that would take action are so dissimilarly situated. It is one thing to "solve" a commons problem when the players are (as in Hardin's classic example) similarly situated around a real commons. The same sacrifice by all presents a focal point for solution. It is much more challenging when some players are large, others small, some have contributed much more to the problem in the past and others in the present, some are rich and some poor, some are advancing and others retreating. Moreover, such differences encourage nations to wrap themselves in self-supporting ethical arguments as to why their share of sacrifice should be lower.

Beyond this, there is substantial variation across regions and nations in both the costs and benefits of coping with climate change (e.g., Heal, 2009; Pielke et al., 2002; Posner \& Weisbach, 2010), or enduring the consequences if policy is ineffective. Thus, both the reality of a politically decentralized 
world and the heterogeneity in costs and benefits push toward a narrowing of scope. However, the more narrow the scope the less globally-shared benefits are likely to justify locally-borne costs. Freerider problems will therefore tend to push narrower analyses toward lesser action.

Another key source of scope disagreement concerns which climate policy options are on the table. Naturally, the costs and benefits of intervention greatly depend upon the nature of the intervention considered. For example, the landmark Stern Review (2007) (of the economics of climate change and consequent policy implications) considers primarily the costs and benefits of mitigation (i.e., emissions reductions). Stavins (2008) and Ellerman et al. (2008) focus their analyses on just one approach to mitigation, cap-and-trade (partly for reasons of political feasibility, which we discuss below). Other studies, such as Schrag (2007b), consider a wider range of options for both adaptation and mitigation.

Some believe that geoengineering options should be seriously considered alongside mitigation efforts (as in Keith, 2000, 2009; Keith, Parson, \& Morgan, 2010; Robock, Marquardt, Kravitz, \& Stenchikov, 2009; Victor, Morgan, Apt, Steinbruner, \& Ricke, 2009). Geoengineering concerns "intentional large-scale manipulation of the environment" (Keith, 2000), such as solar radiation management where aerosols would be injected into the stratosphere to reflect sunlight and counter the effects of global warming. ${ }^{8}$ Though all probably agree that consideration of geoengineering would significantly alter the cost-benefit calculus, agreement rarely goes further.

There are strategic reasons to support or oppose the very consideration of geoengineering. Many believe that even discussing it seriously - let alone funding its research - will undermine mitigation efforts by holding out the hope for a far cheaper, far simpler fix. This concern about the potential moral hazard consequence of geoengineering might help to explain the opposition of many of the climate concerned, and the otherwise surprising support of many climate skeptics. ${ }^{9}$ While there are other reasons to support or oppose it (as in Robock, 2008; Robock et al., 2009), most amount to model, estimate, or values disagreements over the costs and benefits. Concerns about regional climate impacts, ocean acidification, and the like tend to suggest more research and careful consideration, not less.

Other scope issues, however, tend to push geoengineering onto or off of the table. If mitigation efforts turn out to be too little too late, and climate impacts turn out to be extreme (the so-called

\footnotetext{
${ }^{8}$ Other types of geoengineering exist, such as carbon removal or carbon capture and sequestration. The most natural of these approaches - and perhaps the least controversial - involves saving forests that would otherwise be destroyed. Next up would be the planting of forests, as discussed by Stavins (1999). Somewhat more controversial would be capturing and sequestering carbon at the source (as in Schrag, 2007a), which is much more like mitigation than geoengineering. We focus here on the much more controversial approach of solar radiation management.

${ }^{9}$ Many respected scientists among the climate concerned have reluctantly shifted their views of geoengineering, thinking of it as a now necessary evil due to the failure of the world to take significant action on greenhouse gas emissions and pessimism about likely near-term agreements on mitigation. See, for example, comments at the 2010 Asilomar International Conference on Climate Intervention Technologies, near Monterey, California.
} 
"climate emergency" case), we will almost certainly want geoengineering options at the ready. That said, Robock and coauthors stress prudence concerns that push in the other direction. For example, the prospect of geoengineering may be fundamentally too risky (we could inadvertently destroy whole ecosystems!), and we may lack the "moral authority" to act in such a way (should we consider it permissible to manipulate the planet's environment on such a large scale?). As with the moral hazard issue, there seems to be concern that the geoengineering genie, once out of the bottle, will never be returned. Technical capability will leak from one nation to another. Given that capability, individual nations could easily take unilateral steps to geoengineer to benefit their own regions, while imposing risks on the world as a whole. This prospect is frightening and real, but it is not clear whether more or less consideration and research is the best response, or whether serious policymakers should start with the expectation that the genie's escape is inevitable.

Moving beyond geoengineering, whether to consider political feasibility is a source of disagreement that strays into the values domain, as do many scope disagreements. While purists may believe it appropriate to remain focused on technical or moral optima, pragmatists both explicitly consider political feasibility and use political feasibility to constrain the scope of their analyses. For example, legal scholars Posner and Weisbach (2010) take the pragmatic approach in their consideration of climate justice issues; so do some economists (e.g., Summers \& Zeckhauser, 2008). Another example can be found in the aforementioned cap-and-trade analysis. Stavins (2008) chose not to consider other options, such as a straight carbon tax, in part for reasons of political feasibility; cap-and-trade features entitlements for existing interests, and such entitlements significantly reduce organized opposition.

From both positive and normative points of view, it seems a mistake not to consider those elements of political feasibility most likely to bind, for policymakers will surely do so. Ignore politics, and policy recommendations will fall on deaf ears, accomplishing nothing. That said, what is deemed feasible today may differ from what is deemed feasible tomorrow, so care should be taken not to restrict analyses to the politically feasible subset of the day. While public support for mitigation efforts has weakened unexpectedly in some countries (Rosenthal, 2010), a particularly strong hurricane season or other salient events could rapidly shift opinions - and political feasibility - in the other direction. In the summer of 2010, for example, the devastating floods in Pakistan (affecting more than $10 \%$ of its population), and the scorching heat and fires in Russia, surely changed perceptions of climate change risks in those nations (appropriately or not from the scientific perspective).

There are many other scope issues. For example, the non-market consumption of "ecosystem services" advocated by Heal (2009), or the changes in relative market price for "environmental goods and services" advocated by Sterner and Persson (2008), would elevate the projected damages of climate change significantly. Likewise, there is almost no end to the sorts of strategic considerations that Summers and Zeckhauser (2008) raise; individuals and states alike are likely to respond to policy in strategic ways, making "reaction function issues" key to any thorough policy analysis. An example raised by these authors is the consideration of whether future generations might feel bound to policy precedents set by the current generation. If so, action now is more attractive. 


\section{Disagreements over model}

The analyst's model encapsulates how the world is understood to work. We mean this more in the predictive sense than as a full-blown description of reality. This model might tell her what will happen to unemployment should the minimum wage rise, for example, while failing to provide anything resembling a realistic representation of the mechanisms involved. Friedman had much to say on the realism requirement in The Methodology of Positive Economics (1953). While we withhold our views as to whether realistic assumptions are essential, we note that many Friedman critics dispute the ability to predict accurately if they are not. We conclude, with Friedman and critics both, that accurate prediction is most important. That is true whether the policy involves strictly economics or broader issues.

A common problem in policy analysis is that a model can lead to one result as well as its opposite. For example, in an economic model the presence of a market imperfection can change an asset to a liability or vice versa, and rarely can all imperfections be ruled out on first principles. What is to be done? The answer is to turn to empirical analysis. A smidgen of imperfection, for example, may be unlikely to reverse the key predictions of the model. For all key parameters, magnitudes must be measured to provide empirical estimates. Theory tells us where to look for the critical assessments, then empirical analysis undertakes those assessments. Both model and estimate are critical.

What we have just described is the well-established and highly successful methodology for dealing with model disagreements, the scientific method. Once questions of scope and values have been resolved or bargained to agreement, the analyst can employ the standard tools of the social and other sciences to address the issues of model and estimate. Should disagreement then ensue, analysts can ask what evidence would favor one side over the other, and seek out that evidence. If it is difficult to identify definitive or even suggestive evidence, then that indicates that the seeming model disagreement may be a values disagreement in disguise.

We certainly understand that even pure model disagreements can be challenging to resolve. As Rodrik (2010) points out, economics is far better suited to developing and testing individual models than it is at choosing among competing models to apply in a given context. It strikes us that this is true more generally of the broad range of technical tools applied in policy analysis, and that policy analysts of all stripes would be wise to heed Rodrik's call for a greater focus on accurate diagnosis prior to policy prescription. We also understand that strategic actors may not find it in their interest to seek evidence. Pritchett (2002) provides a model, for example, that shows why program advocates might strategically under-invest in evidence (i.e., why it may "pay to be ignorant").

When at an impasse, one approach is to recast model disagreements into simpler estimate disagreements by way of a sufficiently general model. For example, Summers and Zeckhauser (2008, p. 126) discuss the role of increased uncertainty about consequences in determining the desired pace of actions to control climate change; their high-level model shows that the sign of the effect can go either way depending on parameter values. Thus, if different analysts cannot agree on the nuances of a model's mechanisms, a much simpler reduced-form relationship might be distilled. Data can then be used to estimate the reduced-form relationship; and, based on that, the model can be refined. In this way, disagreement can be pushed from model to estimate, then back to model again, in an iterative 
process. Again, this is the domain of the scientific method; and much has been written on the subject since Aristotle, Roger Bacon, and other thinkers first introduced us to the method.

Examples from climate policy: disagreements over model

At bottom, all climate policy should start with the physical science. There is the link between human action - primarily greenhouse gas emissions and deforestation - and atmospheric $\mathrm{CO}_{2}$. Then there is the link between $\mathrm{CO}_{2}$ and the climate. Finally, there are the many links between the climate and sea level, agriculture, disease, storms, desertification, coral bleaching, extinctions, human migrations, and more. On each of these links, the Intergovernmental Panel on Climate Change (IPCC) has played a prominent role in reviewing, distilling, and summarizing scientific findings for policy and other purposes (e.g., IPCC Working Group III, 2007; Parry \& IPCC Working Group II, 2007; Solomon \& IPCC Working Group I, 2007).

The IPCC reports draw on an extraordinary array of international experts, while also serving as consensus documents that must satisfy a diverse group. Though the reports seek to identify potential points of scientific consensus, the science is complex and constantly evolving. At any given point in time, individual scientific assessments can be considerably more pessimistic or optimistic, with the modal assessment tending toward pessimism (e.g., Sokolov et al., 2009). Some critics of the IPCC reports, such as Pielke (2008), consider the IPCC analyses overly focused on $\mathrm{CO}_{2}$ emissions, implying that they therefore underestimate the human impact on the climate. Others, such as Lindzen (2007) and Carter et al. (2006), dispute the scientific conclusions accepted by the IPCC reports, the Stern Review (2007), and seemingly the vast majority of the scientific community. While there is broad agreement on basic aspects of the physical science, there are many disagreements on particulars, both large and small. ${ }^{10}$

Many of these disagreements arise over parameter estimates, but some of them concern the models by which the climate is understood to operate, particularly as it relates to tracing from anthropogenic causes to climatic consequences. Causal attribution is especially important in this debate, because policy implications hinge critically on the causes of global warming, not just on its presence or absence. Even given the same level of warming, different causes imply different interventions - and, likely, different willingness to intervene. ${ }^{11}$

The most fundamental causes of warming are much less in doubt today than they were two decades ago. Still, due to climate variability quite apart from long-term trends, considerable

\footnotetext{
${ }^{10}$ As we mentioned above, these disagreements are likely overblown in popular discourse. Even some prominent former skeptics, most notably Bjorn Lomborg, have become believers in recent years. That said, we agree with Sunstein (2003) that dissent is healthy and even vital. In our view, the climate skeptics and other dissenters very likely strengthen both the policy and the scientific debates.

${ }^{11}$ In a purely rational or economic sense, willingness to counteract harmful climate change should not depend on the underlying cause. However, ethical considerations may be more sensitive to causation. The man-made nature of current warming trends sets the ethical bar for intervention lower than it would be if warming were deemed more "natural."
} 
disagreement will remain over which models best represent different aspects of it. Beyond explaining what is currently happening, what is likely to happen in the future, and why, scientific models can identify potential interventions and project their likely effects. This area of science, extrapolation beyond current data, is inherently more speculative than deduction from existing data, and therefore more prone to disagreement. Fortunately, small-scale experimentation can often help to resolve such disagreements.

To link science and policy, we must quantify and value impacts, bringing them into a common framework for analysis. Here the economics of climate change makes its contribution. Schelling (1992, 2006b), Nordhaus (1994), Daily et al. (2000), Stern (2007, 2008), and Heal (2009) all provide good discussions on this topic, and on some of the many disagreements. The challenge is immense: project the evolution of the world economy, including rates of technological change and economic growth; pin economic valuations on everything from rising seas and migrating humans to amplified diseases and cascading species extinctions; finally, account for how we should value impacts on future generations. To tackle such tasks, some economists build large and complex general equilibrium models ("integrated assessment models"). With scientists, they adapt them to the science. They are then re-adapted as the science evolves. Other economists work with more limited models targeted at particular facets of the problem.

Not surprisingly, fundamental valuation issues, taken up later, drive key disagreements in climate economics. Other disagreements concern parameter estimates within agreed models, such as disagreement over the rate of future consumption growth or the degree to which the marginal utility of consumption declines as consumption increases (that is, the elasticity of the marginal utility of consumption). But many disagreements concern the actual models themselves.

Economists who study climate issues have good reasons for both humility and disagreement. When projecting and quantifying the value of future climate impacts, they must account for the future behavioral responses to climate change (such as migration) in addition to technological change, consumption growth, and all the rest. Yet their models cannot become so complex as to become unwieldy and beyond the capabilities of their human creators. A broad range of micro- and macroeconomic tools must be employed, all of which are themselves the subjects of ongoing debate and evolution within the broader field of economics. And in general, as we saw with the 2008 financial meltdown, economics is much better at explaining the past than at predicting the future.

Uncertainty is a pervasive feature of the physical sciences as well as of the economics (Heal, 2009; Moss \& Schneider, 2000; Oppenheimer, O'Neill, Webster, \& Agrawala, 2007; Schelling, 2007; Sokolov et al., 2009; Summers \& Zeckhauser, 2008; Weitzman, 2007). Not only are individual parameter estimates uncertain, but the fundamental models they feed into are themselves deeply so. While some of this uncertainty will resolve over time - and is itself the subject of modeling and projection - much of it will remain an irremediable feature of the scientific, economic, and policy landscape.

Naturally, there is considerable disagreement over how best to account for this uncertainty, as well as over its policy implications. If the uncertainty is so great as to include the realistic possibility that 
anthropogenic climate change will lead to only minor damages, does that argue against strong action? Such massive uncertainty would also imply the realistic possibility of truly catastrophic damages. Should policymakers demand a traditional level of scientific confidence before deviating from the status quo, or are the risks so great as to justify heroic efforts at course correction? While many of these issues drift into the values domain, modeling the extent and evolution of uncertainty becomes critically important. If, for instance, scientists expect to face considerably less uncertainty next year, policymakers might choose to hold off on major decisions until then. This could, however, be a trap that lulls leaders into a disastrous inertia, particularly if the pace of learning disappoints. ${ }^{12}$

In economics, the classic treatment of uncertainty (drawn from Knight, 1921) suggests that it applies when the potential states of the world are known, but their probabilities are unknown. We believe that with climate change the lack of knowledge goes deeper. Even many potential states of the world are unknown. That is, some - perhaps many - possible future happenings are not considered in scientific or economic models. We label such a situation as ignorance. ${ }^{13}$ Ignorance makes policy disagreements almost inevitable, as imagination competes with evidence to sketch responses to alternative human actions.

\section{Disagreements over estimates}

Given a well-defined model, estimate disagreements encompass broad classes of empirical disagreement. There may be disagreement over parameter values, as well as over appropriate data sets and statistical techniques. To return to an earlier example, economists may agree on a model for labor supply and demand, but disagree on the estimated elasticity of labor supply with respect to wages. Such an elasticity estimate is key to the chronic U.S. debate over the minimum wage (Card \& Krueger, 1997). It is discouraging that one can often predict where a particular economist will stand on this elasticity merely by knowing his general political attitudes. Fuchs et al. (1998) quantified this relationship with a survey of economists. They found that $50.7 \%$ of variation in opinions regarding a minimum-wage increase could be explained by values or political attitudes (vs. only $2.5 \%$ by opinions about the likely change in teen employment, clearly a highly relevant parameter).

As with other types of (apparent) positive disagreement, it is important to reveal estimate disagreements that are in fact hidden values disagreements. If left unrecognized, they can severely complicate the way forward. Even once such values differences have been separated, however, empirical challenges will likely remain. Luckily these challenges, independent of other types of disagreement, are often quite tractable. As with the model issues discussed earlier, the complete scientific arsenal can be brought to bear.

\footnotetext{
${ }^{12}$ Even less optimistically, there is also the possibility that scientific uncertainty will worsen as the science and politics co-evolve (Sarewitz, 2004), or that the quest for objective truth is fundamentally misguided (Oreskes, 2004b).

${ }^{13}$ Zeckhauser (1991, pp. 16-17) introduces this term in the context of the climate debate.
} 


\section{Examples from climate policy: disagreements over estimates}

While there is considerable disagreement over models, there is also plenty of agreement, at least among the vast majority of expert assessors. Many economists employ the same general-equilibrium models; and most scientists agree on the physics behind the greenhouse effect, the basic mechanics of ocean currents, and the like. Even given the same models, however, this leaves economists and climate scientists considerable room to disagree over estimates of the parameters that feed into those models.

Many of these disagreements naturally concern the estimates used as inputs to various models. These include physical science estimates such as the half-life of $\mathrm{CO}_{2}$ in the atmosphere (itself the output of carbon cycle models), economic estimates such as the rate of consumption growth, interventionrelated estimates such as the rate of cost-reducing innovation, and uncertainty-related estimates such as the pace of learning about the actual scale or impact of climate change.

The prominent Stern Report (2007) famously used commonly-employed models in combination with uncommonly-employed parameters, thus producing conclusions that provoked fierce debate (as in, e.g., Dasgupta, 2007; Nordhaus, 2007; Stern, 2008; Weitzman, 2007). Because economic models yield estimates that are quite sensitive to the numerous parameters that they require, efforts like Stern's would nearly always benefit from sensitivity analysis. Rather than leaving critics to find and report the sensitivity of one's conclusions to the various parameter estimates employed, analysts should more proactively and transparently confront sensitivities in the initial analysis. This recommendation is one of strategy as well as of prudence. A sensitivity tester is more likely to be believed.

Sokolov et al. (2009) provide a good example of how estimate disagreements can be confronted fruitfully in both the physical sciences and the economics. These authors update earlier work to account for revised probability distributions over a variety of input parameters, while also exploring the sensitivity of their results to these parameters and other assumptions.

\section{Values disagreements}

Before turning to the three categories of values disagreements, we make some general points. First, we have repeatedly raised the possibility that expressed positive disagreements cloak values disagreements. It can also go the other way: values disagreements, given some critical examination, can turn out to be the product of positive disagreements.

Bruce Rich (2010) describes an illustrative case from India in the third century BCE. King Ashoka, revered to this day in modern India, built a sort of ancient welfare state upon ideas of peace, justice, and compassion. His view of humanity was a fundamentally generous one, recognizing that people respond to principle and sympathy in addition to material interest. Such views represented a sharp break from the existing traditions of his dynasty, typified by Kautilya, an earlier strategist and political philosopher. Kautilya, purported author of the first book on economics, the Arthashastra, held what Rich describes as a more venal view of human nature, even declaring that material well-being is "the most supreme" goal 
of human life. These two ancient characters' philosophies would seem to reflect deep and fundamental differences in values.

However, Kautilya actually justified the supremacy of material well-being on the grounds that "spiritual good (dharma) and sensual pleasures (kama) depend on material well-being." ${ }^{14}$ In fact, he began his treatise by declaring spiritual good or inner harmony - Ashoka's stated aim - to be his own ultimate aim. So traced back to this fundamental point, Ashoka's and Kautilya's philosophies converge.

In a very real sense, then, there is a disagreement here over means, not ends, over the models by which the world is understood to work, not over the goals for which the models are employed. In principle, at least, positive analysis can be brought to bear - even though the disagreement first appears to be values-based.

Interestingly, a mere twenty-two centuries later this argument reemerged within the social sciences, starting with the famed Easterlin Paradox. Easterlin's (1974) findings questioned the tacit connection between income and happiness, suggesting that richer countries were no happier than poorer countries (despite richer individuals tending to be happier than poorer individuals within nations). A large literature has since emerged, some of which recommends that public policy more directly target happiness or well-being, rather than income as a means to those ends (e.g., Bok, 2010; Diener, Lucas, Helliwell, \& Schimmack, 2009; Diener \& Seligman, 2007). While some, such as Amartya Sen $(1985,2000,2009)$, have explicitly argued for other goals altogether - such as capability or substantive freedoms - much of the debate has centered on the most effective means to happiness and well-being.

Schelling (1984) discusses other modern examples where apparent differences in values may actually reflect differences in model. He says that economists "find nothing offensive or coercive about the responses of people to economic opportunities and sanctions," and tend to think that "most people are better at spending their own money than somebody else is at spending it for them." This can manifest as a seemingly values-based preference for free markets and economic conservatism, even when economists and non-economists frequently agree on deeper values. (This may be what Dennis Robertson (1956) had in mind when he equated the economist's task to that of "reducing the preacher's task to manageable dimensions.")

Such views are open to challenge on positive grounds, as one can witness in the burgeoning behavioral economics literature. Empirical findings that demonstrate the economically meaningful effects of altruism, sympathy, or cognitive biases have a bearing on, for example, what seem like values disagreements over the normative appeal of free markets.

We call this class of values operational values. They are values in that they ascribe value to certain types of outcomes (such as promoting free exchange or expanding the role of government), but they are

\footnotetext{
${ }^{14}$ In this belief, he would find agreement with those coterie of today's clergy who preach that faith and prosperity are closely intertwined.
} 
conditional in the sense that they are both justified by deeper values and subject to positive analysis. In this context, Schelling (1984, p. 6) suggests that economics "often helps to diagnose misplaced identification of an ethical issue. And it does this solely by helping to identify what is happening. It is not clarifying ethics; it is only clarifying economics." Schelling uses the debate over the minimum wage to illustrate; there, economics can in principle clarify the true costs and benefits such that the ethical issues might turn out to be far different from those initially recognized.

There is another sense in which positive and values disagreements are often intertwined, which helps to explain why operational values play such a pervasive role in everyday policy disagreement. The fact is, most policy is made under circumstances of extreme uncertainty, often tending toward what we earlier called ignorance. This means that many elements of disagreement are positive in principle only. At least in the short term, barring solid, relevant empirical evidence, disagreement drifts into the values domain. After all, decisions must be made. When there are gaps in model or estimation - and there almost always are - values are left as the predominant players.

We call this class of disagreements provisional values disagreements, because they clearly depend on gaps in positive understanding. Most disagreement over assumptions falls into this category. Absent clear empirical evidence, assumptions are driven by operational values, over which people likely disagree. The U.S. health insurance debate provides a prominent example. The costs and benefits are sufficiently unclear that debate tends to center - at least indirectly - around operational values concerning the appropriate size and role of government. Another example is the debate over cap-andtrade versus other approaches to emissions control. Until the benefits of cap-and-trade were clearly quantifiable, operational values against putting a price on emissions (and thus devaluing our endowment from nature) drove the positions of many. When trying to resolve these sorts of provisional values disagreements, it is often helpful to push them back into the positive domain where some kind of evidence can be brought to bear - with the understanding, of course, that resolution may not come quickly.

While our premise is that it is helpful to uncover the true sources of disagreement, this does not mean that every values disagreement should be driven, on the one side, into the positive domain, or on the other, ever deeper into the values domain. Not every disagreement need be resolved by science and statistics on the one hand, or by the likes of Aristotle and Immanuel Kant on the other. The policy world would grind to a halt if we demanded such rigorous classification and clarification of every disagreement.

After all, Talmudic debate is splendid for training the mind, and deep exegesis is appropriate for Supreme Court opinions; there, we find strong justifications for these deeply investigative methods. But neither of these methods is feasible or appropriate for addressing a vast number and broad array of policy decisions on a timely basis. To do so within affordable time and cost ranges is the challenge of policy analysis. Therefore, we suggest a pragmatic approach that implies a type of cost-benefit calculation: the effort made to classify and clarify should be commensurate with the potential benefit. The higher the potential returns to resolving a disagreement, the more effort should be made. 
We have been primarily talking about principled disagreement and effectively favoring the dispassionate analyst. What Schelling (1984) calls the "ethics of policy" has implicitly held sway, where participants are either dealing with issues in which they have no personal stake, or are trying hard to be "neutral, removed, vicarious, impartial, judicious." As we discussed earlier, we have little to say about the polar opposite case, where participants do not in reality disagree about the merits of a particular policy, but claim that they do for political or other strategic reasons.

The advocate-analyst, as we have described him, is not so extreme. He is simply more likely to engage in what we call partisan values disagreements. These are cases where his bundle of value judgments on standing, criteria, and weights fails to match up with the value judgments of others. Whether his bundle of value judgments reflects professional position, deeply held values, or personal interests, he is more reluctant to compromise than the dispassionate analyst. This makes values disagreements both more frequent and more protracted for advocate-analysts.

The politician is a classic case in point. Politicians serve as advocates for their constituents' interests, though as Levitt (1996) has attempted to quantify, not to the exclusion of party and ideological considerations. We also expect that even the most partisan of politicians is at least somewhat sensitive to the more disinterested facts of the matter. We tend to think of politicians as dynamic optimizers, where their objective functions and constraints are set in part by personal preferences, in part by the structure of the political system, and in part by the composition of their constituencies. Since personal preferences can entail commitments to ideologies and principles considerably beyond a constituency's concerns or one's professional interests, we consider neither politicians nor advocate-analysts in general to be overwhelmingly strategic.

Values disagreements are more likely to arise in some contexts than in others: more on big than small issues, more on ill-defined than well-defined matters. Thus, when a town council discusses whether to build a new incinerator for the town or fix the old one, the discussion is likely to focus on engineering and cost estimates, not on the tradeoff between dollars and health. But if people are deciding on a health plan or an economic-development plan, then values are likely to play a much larger and perhaps predominant role. Moreover, on the bigger issues, we can easily get confused on where our disagreements lie, unless we make a conscientious effort to parse them. ${ }^{15}$

Some values disagreements seem hopelessly intractable, such as the pro-choice and pro-life views in the abortion debate. However, many important values disagreements can be resolved, or at least subjected to fruitful compromise. We reiterate a theme of this essay: simply making the effort to analyze and understand can go a long way. We believe that this is true even in cases where values feature prominently, as in what Pielke (2007) calls "abortion politics" (vs. the more predominantly positive "tornado politics") and what MacRae (1993) calls "adversarial discourse"(vs. "consensual discourse").

\footnotetext{
${ }^{15}$ Textbooks, seeking pedagogic clarity, often illustrate policy analysis with small, well-defined issues. Thus public policy students may be likely to underestimate the influence of values on policy debate.
} 
We make two additional points here, and then others as we talk more specifically about particular types of values disagreement. First, compromise can become unavoidable. Luckily, as Schelling (1984) points out, while "compromising a principle sounds wrong," "compromising between principles is all right." Second, while decisions and compromises must be made, they need not imply resolution of the underlying disagreements. Isaac Levi (1990) has made this point well, namely that difficult decisions must frequently be made before relevant questions have been fully resolved. Thus, a decision is by no means an end to the discussion. As Weimer (1998) points out, in the values domain the analytical approach is inherently "discursive and interpretive" more so than "rationalist-empiricist." Discussion is thus a core part of the process.

We turn now to each of our three categories of values disagreement.

\section{Disagreements over standing}

Disagreements over standing concern who should be considered in an analysis. Whittington and MacRae (1986) and Trumbull (1990) provide thoughtful discussions of the question of standing in costbenefit analysis, which parallels the question of standing in policy analysis more generally. They attempt to resolve the sometimes thorny issues by sheer force of reasoning, which we agree is the right approach. Here, in deciding who should count, there is a clear matter of principle. Agreement should hinge neither on technical feasibility, which may in the end drive the scope of the analysis (as discussed earlier), nor on the more complicated question of how much people or groups should count, which we defer to the upcoming section on weights disagreements. Though Vining and Weimer (2005) combine questions of standing and weights in their discussion of "impact categories," we find it helpful to keep those two questions distinct.

\section{Examples from climate policy: disagreements over standing}

The prospect of climate change affects all people over, potentially, all time. It has thus become a characteristic of climate-change analyses that they consider impacts across all the world's peoples not only now, but for many generations into the future. It is an extremely broad stance on standing; few areas of analysis match it.

While economists prefer an approach to future generations that features no arbitrary time cutoff - by using discounting, which we discuss in the section on weights disagreements below (e.g., Dasgupta, 2007; Stern, 2007; Weitzman, 2007) - it is possible to restrict standing to the current generation since it is the one that will make current decisions, or perhaps to another generation or two. Of course, because the most potentially dire consequences of climate change arise far into the future, excluding future generations tends automatically to tilt in support for the status quo (that is, for taking little or no action).

Regardless of which generations are considered, individual nations might only be expected to pass legislation or sign treaties that make their respective citizens better off, as Posner and Weisbach (2010) point out. This means that we should expect to see broad, global analyses, however noble, give way to narrower national analyses before nations take serious action on climate change. Such analyses would only give at best second-class standing to present or future citizens of other nations, taking their 
interests into account only to the extent that their own citizens wished. However, as we discussed earlier, such parochial analyses would inevitably run afoul of free-rider problems, given that climate change is the quintessential global commons problem. Thus only a coordinated response may be sufficient. This would require that self-interested national analyses feed into some form of global agreement.

\section{Disagreements over criteria}

Often, the very goals of policymaking can be surprisingly hazy. Whether one is projecting or evaluating impact, this can make the measurement of success or failure a shifting, unstable enterprise. When parties hold not merely different yardsticks but handfuls of differing measurement instruments, it is to be expected that disagreement results.

The policy analysis texts by Vining and Weimer (2005) and Stokey and Zeckhauser (1978) both discuss the core rationales for public policy. Their discussions prominently feature efficiency arguments (involving market and government failures), and equity arguments (regarding, for example, distributional concerns). To be sure, such big and fundamental arguments underlie the motivation for policy and thus the criteria by which policy should be judged. Disagreement regarding such values should be brought into the open and discussed, even if not fully resolved.

But there are a great many smaller questions that arise, questions not of the monumental equityvs.-efficiency variety. What are the appropriate dimensions of impact? Should criteria be defined in terms of proximate or ultimate outcomes? What is the relevant time horizon to consider? Even absent disagreement on the big questions, disagreement on these smaller ones can easily hamper, and at times stifle, policy discourse.

While some analysts may prefer to consider only a well-defined set of commonly-considered and readily-quantifiable criteria - economists as a group come to mind - outcomes that are difficult to measure need not be excluded from the analysis. Keeney and Raiffa (1993) discuss subjective attribute scales, proxy attributes, and other methods of integrating the difficult-to-measure into the analytical process. Their focus is multi-attribute decision analysis, a methodology of particular utility to policy analysts.

A good example of difficult-to-measure criteria featuring in the policy dialogue can be found in Amartya Sen's persistent attempts to shift the focus of development and welfare analysis from income and wealth to freedoms and capabilities (e.g., Sen, 2000). Though freedoms and capabilities have so far proved somewhere between difficult and impossible to measure, progress has been made. Sen's conceptual foundations have inspired measures (however imperfect) such as the Human Development Index (United Nations Development Programme, 2009), and even those concepts as yet unmeasured have figured in the policy debate. The report recently issued by France's Commission on the 
Measurement of Economic Performance and Social Progress (Stiglitz, Sen, \& Fitoussi, 2009) can be seen as a modest step in the direction long advocated by Sen. ${ }^{16}$

Even when measurability is not an issue, the question of timeframe invariably arises. Earlier, we mentioned J.M. Keynes and his concern for the short-run. But how should that be defined? What should be its duration? A few years, a decade, or the lifetimes of those now alive? Most often these issues are resolved by weighting outcomes based on how far away they are, as in the discounting approach used in economics. We discuss this topic in the section on weights below, and it becomes particularly important in the case of climate policy.

Examples from climate policy: disagreements over criteria

In climate policy, the predominant method of quantifying and valuing impacts amounts to a large and complex cost-benefit exercise, as exemplified by the Stern Report (2007). ${ }^{17}$ When integrating goals other than efficiency or facing difficulty monetizing certain impacts, this kind of analysis can amount to what Vining and Weimer (2005) call "qualitative" or "modified" cost-benefit analysis. It can be based upon one-good general equilibrium models that consider only overall-mean pricing levels, or it can be based upon more complex models that account for potential shifts in relative prices, as in Sterner and Persson (2008). While approaches differ, all of them involve the valuation of market impacts in presentvalue dollar terms, and many of them also monetize non-market impacts.

Alternatively, non-market impacts can be considered without monetizing them, as in Heal's (2009) consideration of natural capital and ecosystem services. Without pricing the various impacts along a single dimension, however, disagreements can easily become intractable. With so many different dimensions of possible impacts, if a common metric cannot be invoked, it becomes difficult to impossible to develop an integrative analysis. This is not to say that it is not worthwhile, only that such analysis is more challenging and the results less reconcilable with analysis that primarily measures monetized impacts.

Along similar lines, some (perhaps many) participants in the climate change debate seem to include "respect for nature" as an implicit criterion. In this view, the more natural solutions are strongly preferred to the less natural ones, regardless of how the numbers come out. This view is often coupled with an operational distrust of human intervention and a preference for lifestyles that minimize impact on the planet. Such values, including the overall preference for respecting nature, are what we have earlier called operational values; they are very likely underpinned by deeper values and ultimately subject to positive analysis. Some of their proponents might object, but our belief is that, unless studied in such a way, they will tend to be undercounted.

\footnotetext{
${ }^{16}$ A different but related class of arguments has to do with "rights," as in the right to fair trial, education, or health insurance. Such rights may be integrated into an existing analysis by way of constraints on the objective function, rather than requiring a different objective function altogether.

${ }^{17}$ Even when analysis is alternatively framed as "risk analysis" (as in, e.g., Hultman, Hassenzahl, \& Rayner, 2010), rather than cost-benefit analysis, most of the same points apply.
} 
Proponents may believe, for example, that the "respect for nature" criterion would not be necessary if the full consequences of human action could be truly assessed within a cost-benefit or other integrative framework. However, given a less-than-omniscient analysis that is bound to miss or undervalue elements of potentially massive importance, "respect for nature" serves as a good operational value and thus as a useful criterion for analysis. The trouble here is the same as the trouble just discussed with respect to non-market impacts: if we are not trying to be at all precise about things, it is hard to know how much respect is too much or too little.

One of the thorniest areas of criteria disagreement concerns issues of fairness and justice. However they are conceived or measured, should they be included in the analysis? Climate change is, to a large extent, a byproduct of industrialization and development. Today's richest countries have contributed the majority of excess $\mathrm{CO}_{2}$ in the atmosphere, and they continue to contribute by far the largest share in per-capita terms. Many believe that these same advanced countries, therefore, have the greatest responsibility to bear the costs of mitigation and adaptation. This would include compensating poor countries for the climate consequences that they are forced to bear.

Today's developing countries, however, are quickly becoming the greatest emitters of greenhouse gases, led by China, which recently surpassed the United States as the world's leading emitter. If global mitigation efforts are to succeed, there will need to be emission reductions in developing countries; but those countries fear that such reductions would provide a costly drag on their own development efforts. Particularly since the already-developed countries were able to develop without such a hindrance, many believe that it is not fair to require today's developing countries to bear the costs of mitigation (for instance, of using "clean coal" technologies). Again, rich countries would be asked to pick up some of the tab. ${ }^{18}$

There are, broadly, two views on the subject. One is that issues of fairness and justice are unavoidably center-stage, that any kind of global treaty mechanism would need to be viewed as just and fair in order to engender the nearly universal participation that would be required (Vanderheiden, 2008). India's defense of "equity" as central to any international agreement is characteristic of this view (e.g., Ramesh, 2010). Another view is that a more realist-welfarist approach is required, one that sets aside moral theory and focuses instead on reaching forward-looking agreements that make everybody better off (Posner \& Sunstein, 2009; Posner \& Weisbach, 2010). In the former view, including justice and fairness in the analysis is indispensable to reaching agreement and moving forward; and in the latter, including such criteria does just the opposite, making mutually-beneficial agreement far less likely. One who believes that different nations' conceptions of fairness and justice are irreconcilably different will likely reside in the latter camp.

The politics of this particular disagreement will play out on multiple levels. There will be the national politics, what citizens view as fair or unfair; and then there will be the international politics,

\footnotetext{
${ }^{18}$ This prospect becomes complicated by other issues of international political economy. For instance, if rich countries view themselves as increasingly competing over world markets with up-and-coming developing countries, they will be loath to help finance their competitors' energy production.
} 
what world leaders consider (or pose as) fair or unfair in their multilateral negotiations. To be sure, all participants will wrap their arguments in the mantle of fairness, but such mantles, like beauty, are in the eyes of the beholders. This is an area in which politics is likely to play a particularly important role, and analysts would be wise to be sensitive to political feasibility. Posner and Weisbach (2010) argue that such feasibility should be an important criterion in an overall analysis, but this view does not get broad agreement. It may be that many of today's analysts are recommending the policies they would like to see rather than those they believe to be politically feasible, because they think their more extreme views will push policies in the right direction. Beyond that, as we have noted earlier, there is always the concern that the feasible set will change - perhaps rapidly - so analysts are also wise to consider options that might become feasible tomorrow, perhaps as physical events unfold.

\section{Disagreements over weights}

The arms debate in the 1960s raised a fundamental disagreement, sometimes pithily summarized as "Are we better dead than Red?" Of course, underlying this phrasing was the implicit assumption that a thermonuclear exchange between the U.S.S.R. and the U.S. was inevitable or highly likely, a point strongly pushed by groups espousing certain values. Levine (1963) dissects the arms debate of that era, providing an early and insightful analysis of the interplay of values and models in policy debates. He points out that "competition among value judgments" should not be confused with inconsistency. For example: "An individual may place a high value on peace, and may at the same time place a high value on some other policy goal, the pursuit of which involves a risk of war. These values may well compete for policy emphasis, but they are not inconsistent."

This question of policy emphasis is precisely what we mean when we consider disagreements over weights. Once we know who counts (standing) and what counts (criteria), we need to agree on what weight these different elements deserve in the overall analysis.

It is frequently the case that decisions regarding standing and criteria are easier than the corresponding decisions regarding their weights. What is fundamentally valued, after all, seems to vary far less across time and people than how to trade off what is valued. In other words, it is the question of emphasis that tends to vary more than do fundamentals. It should not be surprising, therefore, that people come to disagree most frequently over weights.

The potential saving grace for disagreements over weights is sensitivity analysis. Assuming that an analysis is structured so that varying weights can be given to various components, one can easily see how sensitive the conclusions are - or are not - to reasonable choices of weights. Since conclusions rarely teeter on the knife's edge, there is often scope to tolerate some disagreement over weights. This means that we can agree to disagree, until and unless our disagreement leads to different policy conclusions. ${ }^{19}$

\footnotetext{
${ }^{19}$ While conducting sensitivity analysis is a quantitative exercise, consuming such an analysis need not be. Of primary interest to policymakers and other consumers will be the question: how far must weights be tilted to overturn the primary conclusions of the analysis? In most cases, the answer to this question can be communicated in a simple, direct way that does not overly complicate the core analysis.
} 
One disturbing feature of weights disagreements is that they are frequently hidden. The proponent for one set of weights simply uses them, and says nothing. Had Justice Brandeis been asked to comment on weights disagreements, he might have remarked: "Let us start with sunlight, thus making them highly visible." Here as elsewhere, we believe that greater clarity in the sources of our disagreements can lead to better policy by suggesting further investigation, enabling coherent compromise, and perhaps encouraging greater sharing of information.

\section{Examples from climate policy: disagreements over weights}

With choices regarding standing and criteria being so broad and inclusive, as they tend to be in climate policy, there is tremendous scope for disagreement over weights. And here, small differences in weights can lead to large differences in conclusions. In particular, the Stern Report (2007) sparked a heated discussion of two key weights issues, interpersonal and intertemporal, to which policy conclusions are especially sensitive (Dasgupta, 2007, 2008; Heal, 2009; Nordhaus, 2007; Stern, 2008; Weitzman, 2007).

In the case of interpersonal weighting, the question is how to weight different individuals within a given generation or time period. Even making the heroic assumption that benefits can be measured in dollar terms, the answer still depends on the overall policy goal. If the purpose is merely to produce the greatest total dollar value, then all dollars should count the same, to whomever they go. An alternate purpose, also widely employed, is to generate the greatest sum of utility or well-being. In this case, dollars going to different individuals must be weighted differently. This is because $\$ 10$ to a desperately poor individual has much more impact than $\$ 10$ to a millionaire. Economists account for this by looking at the elasticity of marginal utility with respect to consumption, or eta for short (after the Greek letter that represents it in equation form). Eta indicates how the benefits from a dollar diminish as one gets richer.

One reason why disagreements over eta go beyond estimate disagreements, to be resolved empirically, is that economists cannot actually measure utility. What economists can do is infer utility differences, but not in a way that facilitates interpersonal comparisons, which is exactly what would be needed to estimate eta. Therefore, eta becomes a values choice, sometimes called the "preference for equity." It sounds like a tangible parameter that can be measured, but in reality it amounts to a preference over how to weight impacts on the rich vs. the poor. As with any preference, it can be the subject of much disagreement.

The implications to climate policy are profound. In strict market-value terms, illness and death in rich countries is extremely costly; in poor countries, it is far less so (consider, e.g., foregone wages in the two cases). While those most affected by climate policy will be the world's poorest and most vulnerable, they could count little in the analysis, depending on the choice of eta. As a simple example, consider the possibility that global warming leads to a sizeable increase in illness and death in poor countries, but a small decrease in cold-weather-related illness and death in rich countries. Depending on eta, warming could seem beneficial on net. 
Turning to the case of intertemporal weighting, the question becomes how to weight individuals across different generations or time periods. Here, appropriate weighting sounds like a more clear-cut values issue. However, many have argued that time preference is something that can be measured, for example by observing individuals' intertemporal-choice behaviors, interest rates, etc. Stern (2007), however, chose a "pure rate of time preference" that gave greater weight to the current generation only by a slight amount (to account for the remote possibility of future human extinction), based on what he considered the fundamental moral equivalence of current and future generations. While Stern's eta acted to discount impacts on future generations because of their greater projected wealth, in principle Stern did not otherwise give greater weight to the current generation. This is an aspect of his analysis that has provoked considerable debate, with some agreeing with it and others disagreeing, often sharply.

Summers and Zeckhauser (2008) advocate a different approach, one that pragmatically considers the current generation as more heavily weighted than future generations because it is the one making decisions, but does not necessarily distinguish, or distinguishes only slightly, among future generations. This accords with a kind of quasi-hyperbolic or beta-delta discounting model, such as those employed to understand individuals' intertemporal-choice behaviors (e.g., Laibson, 1997). In the SummersZeckhauser view, the beta (the discrete difference between now and later) is important, the delta (the continuous difference between all time periods) much less so. ${ }^{20}$

Schelling (2006b) offers another view, suggesting that individuals' personal trade-offs over time offer a poor guide to how individuals think about making transfers to (or incurring costs on behalf of) unrelated individuals in the distant future. Rather, he suggests that we think about individuals distant in time much the way we do individuals distant in space, such as when we consider foreign aid transfers. This accords with Stern's approach, where the pure rate of time preference is effectively zero. Schelling goes further, however, by pointing out that the costs of climate policy will largely be borne by the relatively wealthy while the benefits will more predominantly accrue to the relatively poor (since they are most vulnerable to adverse climate impacts). Since tomorrow's poorest will still be poor relative to today's richest, the startling implication is that the implied discount rate could be negative. This would push even more heavily toward costly action today, as a sort of transfer from today's rich to tomorrow's poor. $^{21}$

\footnotetext{
${ }^{20}$ Such beta-delta discounting will lead to dynamically inconsistent behavior. As a generation gains control, it will reverse established policy in favor of itself. However, if today's generation sets a precedent for future action, the next generation may follow as a means to assure adherence by other future generations. (Note that a desirable climate is not a commodity that can be bought for money. If it were, traditional market-rate discounting would pave the path to Pareto-superior outcomes: invest now and buy climate later.)

${ }^{21}$ However, Hylland and Zeckhauser (1979) argue that it is almost always the case that redistribution is more effectively carried out through the tax and transfer system than it is through structuring public programs that are not addressed to redistribution, such as climate policy. The implication might be that rather than provide climate relief, the present generation should shift resources to the future, say by taxing itself more and thus lowering a deficit that will ultimately have to be paid, or even raising a surplus that will be carried forward. Along these lines,
} 
While there is considerable disagreement regarding both interpersonal and intertemporal weighting, this is an area in which sensitivity analysis might be employed with relative ease. There are choices of eta, delta, and perhaps beta, all of which might be varied to consider how sensitive conclusions are to the various choices. The common analytical practice of assigning values to some Greek letters without pointing out how those values drive results strikes us as unwise, and perhaps unfair.

It may be that the economic approach to weighting - the etas and the deltas - is appropriate for global, impartial analyses, but inadequate for national analyses that are more partial by nature. A more politically relevant analysis might weight outcomes the way individuals and nations implicitly do in practice, where weights are derived by more nuanced and subjective notions of distance and concern. Here, "us" and "them" are matters of degree, with people and nations both demonstrating more concern for their nearest neighbors - geographically, culturally, ethnically, politically, historically - than those more distant. Time is an additional source of distance, one that may work to blur the other distinctions. Thus, we may distinguish between Americans and Canadians today, but disregard this distinction when considering individuals several generations hence.

The mainstream economic approach, wherein a single discount rate generally suffices for all individuals, would seem to presume that such distinctions can be blurred. While this approach may work for the far future, more differentiated approaches to weighting may be more politically relevant in the shorter term. In other words, the distinctions may matter. Perhaps this could be integrated into new analyses with an additional factor for interpersonal weighting. There would be weighting by marginal utility, but then also by distance, however measured. ${ }^{22}$

Climate policy brings to bear other weights issues that play a potentially important role. There is the question of how to weight outcomes that are uncertain - perhaps even extremely low in probability - but irreversible or infinitely bad. Weitzman (2007) allows the infinitely bad to swamp the analysis, but Summers and Zeckhauser (2008) counter that no loss merits negative infinity. They note, for example, that individuals risk death to themselves and loved ones with family automobile trips.

Climate policy also raises the question of whether to weight errors of commission more heavily than errors of omission. In daily life and politics we tend to do so; however, it is unclear whether this is the most rational approach to analysis and policy. Holding uncertainty levels and all else constant, should $\$ x$ in damage that comes about by inaction be weighted more lightly than $\$ x$ in damage that

Schelling (2006b) and Hulme (2009), among others, discuss the relative attractiveness of more direct, development-related spending in the present-day.

${ }^{22}$ Of course, many will prefer to keep such weights implicit rather than explicit, perhaps for reasons of political correctness. While we do not deny the pressures that push in this direction, we wish to tilt toward transparency. After all, it is exceptionally difficult to have reasoned debates about policies when differences are driven by unspoken differences in weights. 
comes about by action? An affirmative answer would strongly favor the status quo, which may or may not be a good thing. This issue is particularly relevant to the debate over geoengineering. 


\section{THE WAY FORWARD}

From a U.S. vantage point, climate policy has begun to look in some ways like welfare policy did in the 1990s. The welfare reform of 1996, which focused on the pathway from welfare to work, followed decades of analysis and debate over federal welfare policy. Over those decades, many in the political and public spheres recognized a need for action, and high-quality research within and without government grew in both volume and sophistication (Besharov \& Call, 2010; Ellwood, 2003; Kraemer, Dickhoven, Tierney, \& King, 1987). But despite a great deal of analysis and interest, confusion and disagreement reigned. Even when the growing body of evidence was not altogether ignored by the political process, it was re-interpreted and re-spun to serve as ammunition for all sides of the debate (Bane, 2001; Haskins, 1991; Kraemer et al., 1987; Zuckerman, 2000). Dueling models, grown from differing assumptions and tailored for differing concerns, pulled policy in different directions (Ellwood, 2003).

Then there was a convergence in values. President Clinton joined Congressional Republicans and others in believing that the goal was "a hand up, not a hand out" - and he articulated this goal clearly (Besharov \& Call, 2010; Ellwood, 1996, 2003). Though agreement on core values was hardly unanimous (Reich, 2002), a political decision had effectively been made. This then focused the debate on positive and political disagreements, where analysis and the intellectual framework provided by researchers could be most useful (Ellwood, 2003). Major policy reform quickly followed.

At least in the U.S., climate policy is likely to follow a similar path, from political decision to policy reform. But while Ellwood (2003) rightly points out that the political process has the responsibility of choosing values in a democracy, we believe that analysis can play an important facilitating role. Specifically, good analysis can clarify values trade-offs and identify those values decisions upon which optimal policy decisions most critically rest. Such analysis attends to both the positive and values aspects of the policy problem.

As researchers and policy analysts, many of us share the hope of welfare veterans like Besharov (2009) and Ellwood (2003) - that we can get better and better at using our work to facilitate good policymaking. To that end, we recommend greater attention to the fundamental sources of policy disagreement: scope, model, and estimate in the positive domain; and standing, criteria, and weights in the values domain.

For new analysis conducted in the future, we go further. We propose that it be organized so that choices of scope, model, estimate, standing, criteria, and weights are clearly specified. Being explicit and transparent in each of these elements will help to facilitate assessment, comparison, and debate, within both the research and policymaking communities.

Specifically, we propose that policy analysis be structured in the following manner:

1. Introduction

2. Analytic framework

a. Scope 

b. Model
c. Estimation
d. Standing
e. Criteria
f. Weights

3. Results

4. Sensitivity analyses

5. Conclusions and recommendations

Organizing analysis in this way will not end disagreement, but it will lay bare its sources. And as Sunstein (2003) argues, disagreement itself is healthy for society. It helps us to move from poor or even good policies to better ones, and it is particularly effective at doing this when disagreements are clear, reasoned, and inclusive. Transparent, well-organized policy analysis can help to facilitate disagreement and thus good policymaking, thereby turning heat into light. 


\section{REFERENCES}

Anderegg, W. R. L., Prall, J. W., Harold, J., \& Schneider, S. H. (2010). Expert credibility in climate change. Proceedings of the National Academy of Sciences, 107(27), 1210712109. doi:10.1073/pnas.1003187107

Aumann, R. J. (1976). Agreeing to Disagree. The Annals of Statistics, 4(6), 1236-1239.

Baicker, K., \& Chandra, A. (2009). Uncomfortable Arithmetic -- Whom to Cover versus What to Cover. New England Journal of Medicine, 362(2), 95-97. doi:10.1056/NEJMp0911074

Bane, M. J. (2001). Presidential Address -- Expertise, Advocacy and Deliberation: Lessons from Welfare Reform. Journal of Policy Analysis and Management, 20(2), 191-197. doi:10.1002/pam.2021

Besharov, D. J. (2009). Presidential address: From the Great Society to continuous improvement government: Shifting from “does it work?” to "what would make it better?”. Journal of Policy Analysis and Management, 28(2), 199-220. doi:10.1002/pam.20423

Besharov, D. J., \& Call, D. M. (2010). JPAM Classics: Editor's Introduction. In D. J. Besharov \& D. M. Call (Eds.), Poverty, Welfare, and Public Policy. Wiley-Blackwell.

Bok, D. (2010). The Politics of Happiness. Princeton University Press.

Boykoff, M. T., \& Boykoff, J. M. (2004). Balance as bias: global warming and the US prestige press. Global Environmental Change, 14(2), 125-136. doi:10.1016/j.gloenvcha.2003.10.001

Card, D., \& Krueger, A. B. (1994). Minimum Wages and Employment: A Case Study of the Fast-Food Industry in New Jersey and Pennsylvania. The American Economic Review, 84(4), 772-793.

Card, D., \& Krueger, A. B. (1997). Myth and measurement: the new economics of the minimum 
wage. Princeton University Press.

Card, D., \& Krueger, A. B. (2000). Minimum Wages and Employment: A Case Study of the Fast-Food Industry in New Jersey and Pennsylvania: Reply. The American Economic Review, 90(5), 1397-1420.

Carter, R. M., De Freitas, C. R., Goklany, I. M., Holland, D., \& Lindzen, R. S. (2006). The Stern Review: A Dual Critique (Part I: The Science). World Economics, 7(4), 167-198. doi:Article

Daily, G. C., Söderqvist, T., Aniyar, S., Arrow, K., Dasgupta, P., Ehrlich, P. R., Folke, C., et al. (2000). The Value of Nature and the Nature of Value. SCIENCE, 289, 395-396.

Dasgupta, P. (2007). Commentary: The Stern review's economics of climate change. National Institute Economic Review, 199(1), 4-7.

Dasgupta, P. (2008). Discounting climate change. Journal of Risk and Uncertainty, 37(2), 141169. doi:10.1007/s11166-008-9049-6

Diener, E., Lucas, R., Helliwell, J., \& Schimmack, U. (2009). Well-Being for Public Policy. New York: Oxford University Press.

Diener, E., \& Seligman, M. E. P. (2007). Measure for Measure: The case for a national wellbeing index. Science \& Spirit, 17(2), 36-37. doi:10.3200/SSPT.17.2.36-37

Dixit, A. K., \& Weibull, J. W. (2007). Political polarization. Proceedings of the National Academy of Sciences, 104(18), 7351-7356. doi:10.1073/pnas.0702071104

Easterlin, R. A. (1974). Does economic growth improve the human lot? In P. A. David \& M. W. Reder (Eds.), Nations and Households in Economic Growth: Essays in Honor of Moses Abramovitz. New York: Academic Press.

Editor. (2009, July 26). Health Care Reform and You. The New York Times. 
Ellerman, A. D., Webster, M. D., Parsons, J., Jacoby, H. D., \& McGuinness, M. (2008). Capand-Trade: Contributions to the Design of a U.S. Greenhouse Gas Program. Cambridge, MA: MIT Center for Energy and Environmental Policy Research.

Ellwood, D. T. (1996). Welfare reform as I knew it. The American Prospect, (26), 22.

Ellwood, D. T. (2003). From research to social policy and back again: Translating scholarship into practice through the starry eyes of a sometimes scarred veteran. Social Policy Journal of New Zealand, 6-28.

Fischer, F., \& Forester, J. (1993). Editors' Introduction. In F. Fischer \& J. Forester (Eds.), The argumentative turn in policy analysis and planning (pp. 1-17). Taylor \& Francis.

Friedman, M. (1953). The Methodology of Positive Economics. In Essays in positive economics (pp. 3-43). University of Chicago Press.

Fuchs, V. R., Krueger, A. B., \& Poterba, J. M. (1998). Economists' Views about Parameters, Values, and Policies: Survey Results in Labor and Public Economics. Journal of Economic Literature, 36(3), 1387-1425.

Haskins, R. (1991). Congress Writes a Law: Research and Welfare Reform. Journal of Policy Analysis and Management, 10(4), 616. doi:10.2307/3324988

Heal, G. (2009). Climate Economics: A Meta-Review and Some Suggestions for Future Research. Review of Environmental Economic Policy, 3(1), 4-21. doi:10.1093/reep/ren014

Hulme, M. (2009). Why we disagree about climate change : understanding controversy, inaction and opportunity. Cambridge, UK ;: Cambridge University Press.

Hultman, N. E., Hassenzahl, D. M., \& Rayner, S. (2010). Climate Risk. Annual Review of Environment and Resources, 35(1). 
Hylland, A., \& Zeckhauser, R. (1979). Distributional Objectives Should Affect Taxes but Not Program Choice or Design. The Scandinavian Journal of Economics, 81(2), 264-284.

IPCC Working Group III. (2007). Climate Change 2007 - Mitigation of Climate Change: Working Group III Contribution to the Fourth Assessment Report of the IPCC. Cambridge University Press.

Jenkins-Smith, H. C. (1982). Professional Roles for Policy Analysts: A Critical Assessment. Journal of Policy Analysis and Management, 2(1), 88. doi:10.2307/3323652

Keeney, R. L., \& Raiffa, H. (1993). Decisions with Multiple Objectives: Preferences and Value Trade-offs. New York: Cambridge University Press.

Keith, D. W. (2000). GEOENGINEERING THE CLIMATE: History and Prospect. Annual Review of Energy and the Environment, 25(1), 245-284. doi:10.1146/annurev.energy.25.1.245

Keith, D. W. (2009). Why Capture CO2 from the Atmosphere? Science, 325(5948), 1654-1655. doi:10.1126/science.1175680

Keith, D. W., Parson, E., \& Morgan, M. G. (2010). Research on global sun block needed now. Nature, 463(7280), 426-427. doi:10.1038/463426a

Keynes, J. M. (1923). A tract on monetary reform. Macmillan and Co., Limited.

Keynes, J. N. (1904). The scope and method of political economy. Macmillan.

Knight, F. H. (1921). Risk, uncertainty and profit. Houghton Mifflin Company.

Kousky, C., \& Zeckhauser, R. (2009, November). Costing Clunkers: The Problem of Scope Neglect. Mimeo.

Kraemer, K. L., Dickhoven, S., Tierney, S. F., \& King, J. L. (1987). Datawars: the politics of modeling in Federal policymaking. Columbia University Press. 
Kraft, M. E., \& Furlong, S. R. (2004). Public policy: politics, analysis, and alternatives. CQ Press.

Laibson, D. (1997). Golden Eggs and Hyperbolic Discounting. Quarterly Journal of Economics, 112(2), 443-477. doi:10.1162/003355397555253

Levi, I. (1990). Hard Choices. Cambridge University Press.

Levine, R. A. (1963). The arms debate. Harvard University Press.

Levitt, S. D. (1996). How Do Senators Vote? Disentangling the Role of Voter Preferences, Party Affiliation, and Senator Ideology. The American Economic Review, 86(3), 425-441.

Lindzen, R. S. (2007). Taking GreenHouse Warming Seriously. Energy \& Environment, 18(7), 937-950. doi:10.1260/095830507782616823

Lipsey, M. W., Freeman, H. E., \& Rossi, P. H. (2004). Evaluation: a systematic approach (7th ed.). Thousand Oaks, Calif.: Sage Publications.

MacRae, D. (1993). Guidelines for Policy Discourse: Consensual versus Adversarial. In F. Fischer \& J. Forester (Eds.), The argumentative turn in policy analysis and planning (pp. 1-17). Taylor \& Francis.

Miles, R. E. (1978). The Origin and Meaning of Miles' Law. Public Administration Review, 38(5), 399-403.

Morris, S. (1995). The Common Prior Assumption in Economic Theory. Economics and Philosophy, 11, 227-253.

Moss, R. H., \& Schneider, S. H. (2000). Towards Consistent Assessment and Reporting of Uncertainties in the IPCC TAR. In R. Pachauri, T. Taniguchi, \& K. Tanaka (Eds.), Guidance papers on the cross cutting issues of the third assessment report of the IPCC (pp. 33-51). IPCC. 
Neumark, D., \& Wascher, W. (2000). Minimum Wages and Employment: A Case Study of the Fast-Food Industry in New Jersey and Pennsylvania: Comment. The American Economic Review, 90(5), 1362-1396.

Nordhaus, W. D. (1994). Managing the global commons: the economics of climate change. MIT Press.

Nordhaus, W. D. (2007). A review of the Stern Review on the economics of climate change. Journal of Economic Literature, 45(3), 686-702.

Oppenheimer, M., O'Neill, B. C., Webster, M., \& Agrawala, S. (2007). CLIMATE CHANGE: The Limits of Consensus. Science, 317(5844), 1505-1506. doi:10.1126/science.1144831

Oreskes, N. (2004a). Beyond the ivory tower: The scientific consensus on climate change. Science, 306(5702), 1686.

Oreskes, N. (2004b). Science and public policy: what's proof got to do with it? Environmental Science \& Policy, 7(5), 369-383. doi:10.1016/j.envsci.2004.06.002

Parry, M. L., \& IPCC Working Group II. (2007). Climate change 2007: Impacts, Adaptation and Vulnerability. Cambridge University Press.

Pear, R., \& Herszenhorn, D. M. (2009, December 1). No Big Cost Rise In U.S. Premiums Is Seen in Study. The New York Times.

Pielke, R. A. (2007). The honest broker: making sense of science in policy and politics. Cambridge University Press.

Pielke, R. A. (2008). A broader view of the role of humans in the climate system. Physics Today, 61(11), 54. doi:10.1063/1.3027992

Pielke, R. A., Stohlgren, T., Schell, L., Parton, W., Doesken, N., Redmond, K., Moeny, J., et al. (2002). Problems in evaluating regional and local trends in temperature: an example from 
eastern Colorado, USA. International Journal of Climatology, 22(4), 421-434.

doi:10.1002/joc.706

Pooley, E. (2010). The climate war : true believers, power brokers, and the fight to save the earth (1st ed.). New York: Hyperion.

Posner, E. A., \& Sunstein, C. R. (2009). Should Greenhouse Gas Permits Be Allocated on a Per Capita Basis? CALIFORNIA LAW REVIEW, 97, 51.

Posner, E. A., \& Weisbach, D. (2010). Climate Change Justice. Princeton University Press.

Pritchett, L. (2002). It pays to be ignorant: a simple political economy of rigorous program evaluation. The Journal of Policy Reform, 5(4), 251. doi:10.1080/1384128032000096832

Ramesh, J. (2010, June 30). Statement of Mr. Jairam Ramesh. Presented at the 7th Major Economies Forum, Rome, Italy. Retrieved from http://moef.nic.in/downloads/publicinformation/speech-mef.pdf

Reich, R. B. (2002). Introduction: Working Principles -- From Ending Welfare to Rewarding Work. In R. Kuttner (Ed.), Making work pay: America after welfare. New York: New Press.

Rich, B. (2010). To Uphold the World. Beacon.

Robertson, D. H. (1956). Economic commentaries. Staples Press.

Robock, A. (2008). 20 reasons why geoengineering may be a bad idea. Bulletin of the Atomic Scientists, 64(2), 14-18. doi:10.2968/064002006

Robock, A., Marquardt, A., Kravitz, B., \& Stenchikov, G. (2009). Benefits, risks, and costs of stratospheric geoengineering. Geophysical Research Letters, 36. doi:200910.1029/2009GL039209

Rodrik, D. (2010). Diagnostics before Prescription. Journal of Economic Perspectives, 24(3), 33- 
44. doi:10.1257/jep.24.3.33

Rosenthal, E. (2010, May 24). Climate Fears Turn to Doubts Among Britons. The New York Times. Retrieved from http://www.nytimes.com/2010/05/25/science/earth/25climate.html Sabatier, P. A., \& Weible, C. M. (2007). The Advocacy Coalition Framework: Innovations and Clarifications. In P. A. Sabatier (Ed.), Theories of the policy process (pp. 189-220). Westview Press.

Sarewitz, D. (2004). How science makes environmental controversies worse. Environmental Science \& Policy, 7(5), 385-403. doi:10.1016/j.envsci.2004.06.001

Schelling, T. C. (1984). Choice and consequence. Harvard University Press.

Schelling, T. C. (1992). Some Economics of Global Warming. The American Economic Review, 82(1), 1-14.

Schelling, T. C. (2006a). What Makes Greenhouse Sense? In Strategies of commitment and other essays (pp. 27-44). Cambridge, Mass.: Harvard University Press.

Schelling, T. C. (2006b). Intergenerational and International Discounting. In Strategies of commitment and other essays. Cambridge, Mass.: Harvard University Press.

Schelling, T. C. (2007). Climate Change: The Uncertainties, the Certainties and What They Imply About Action. The Economists' Voice, 4(3). doi:10.2202/1553-3832.1276

Schrag, D. P. (2007a). Preparing to Capture Carbon. Science, 315(5813), 812-813. doi:10.1126/science.1137632

Schrag, D. P. (2007b). Confronting the Climate-Energy Challenge. Elements, 3(3), 171-178. doi:10.2113/gselements.3.3.171

Sen, A. (1985). Well-Being, Agency and Freedom: The Dewey Lectures 1984. The Journal of Philosophy, 82(4), 169-221. 
Sen, A. (2000). Development as Freedom. Anchor.

Sen, A. (2009). The Idea of Justice. Harvard University Press.

Sokolov, A. P., Stone, P. H., Forest, C. E., Prinn, R., Sarofim, M. C., Webster, M., Paltsev, S., et al. (2009). Probabilistic Forecast for Twenty-First-Century Climate Based on Uncertainties in Emissions (Without Policy) and Climate Parameters. Journal of Climate, 22(19), 5175-5204.

Solomon, S., \& IPCC Working Group I. (2007). Climate change 2007: The Physical Science Basis. Cambridge University Press.

Stavins, R. N. (1999). The Costs of Carbon Sequestration: A Revealed-Preference Approach. The American Economic Review, 89(4), 994-1009.

Stavins, R. N. (2008). Addressing climate change with a comprehensive US cap-and-trade system. Oxford Review of Economic Policy, 24(2), 298-321. doi:10.1093/oxrep/grn017

Stern, N. (2008). The Economics of Climate Change. American Economic Review, 98(2), 1-37. doi:10.1257/aer.98.2.1

Stern, N. H. (2007). The economics of climate change. Cambridge University Press.

Sterner, T., \& Persson, U. M. (2008). An Even Sterner Review: Introducing Relative Prices into the Discounting Debate. Rev Environ Econ Policy, 2(1), 61-76. doi:10.1093/reep/rem024

Stiglitz, J., Sen, A., \& Fitoussi, J. (2009). Report by the Commission on the Measurement of Economic Performance and Social Progress. Paris: Commission on the Measurement of Economic Performance and Social Progress.

Stokey, E., \& Zeckhauser, R. (1978). A primer for policy analysis. W. W. Norton.

Summers, L., \& Zeckhauser, R. (2008). Policymaking for posterity. Journal of Risk and Uncertainty, 37(2), 115-140. doi:10.1007/s11166-008-9052-y 
Sunstein, C. R. (2003). Why societies need dissent. Harvard University Press.

Sunstein, C. R. (2009). Going to Extremes. Oxford University Press US.

Trumbull, W. N. (1990). Who Has Standing in Cost-Benefit Analysis? Journal of Policy Analysis and Management, 9(2), 201-218.

Tversky, A., \& Kahneman, D. (1974). Judgment Under Uncertainty: Heuristics and Biases. Science, 185, 1124-1131.

United Nations Development Programme. (2009). Human development report 2009. New York: Palgrave Macmillan.

Vanderheiden, S. (2008). Atmospheric justice. Oxford University Press US.

Victor, D. G., Morgan, M. G., Apt, J., Steinbruner, J., \& Ricke, K. (2009). The geoengineering option. Foreign Affairs, 88(2), 69-76.

Vining, A. R., \& Weimer, D. L. (2005). Policy analysis: concepts and practice (4th ed.). Upper Saddle River, NJ: Pearson Prentice Hall.

Weimer, D. L. (1998). Policy Analysis and Evidence: A Craft Perspective. Policy Studies Journal, 26(1), 114-128. doi:10.1111/j.1541-0072.1998.tb01928.x

Weimer, D. L. (2005). Institutionalizing Neutrally Competent Policy Analysis: Resources for Promoting Objectivity and Balance in Consolidating Democracies. Policy Studies Journal, 33(2), 131-146. doi:10.1111/j.1541-0072.2005.00098.x

Weimer, D. L. (2002). Enriching Public Discourse: Policy Analysis in Representative Democracies. The Good Society, 11(1), 61-65.

Weitzman, M. L. (2007). A review of the Stern Review on the economics of climate change. Journal of Economic Literature, 45(3), 703-724.

Whittington, D., \& MacRae, D. (1986). The Issue of Standing in Cost-Benefit Analysis. Journal 
of Policy Analysis and Management, 5(4), 665-682.

Zeckhauser, R. (Ed.). (1991). Strategy and choice. MIT Press.

Zuckerman, D. M. (2000). Welfare Reform in America: A Clash of Politics and Research. Journal of Social Issues, 56(4), 587-600. doi:10.1111/0022-4537.00186 